\title{
Altered Thermal Selection Behavior in Mice Lacking Transient Receptor Potential Vanilloid 4
}

\author{
Hyosang Lee, ${ }^{1}$ Tohko Iida, ${ }^{1}$ Atsuko Mizuno, ${ }^{2}$ Makoto Suzuki, ${ }^{2}$ and Michael J. Caterina ${ }^{1}$ \\ ${ }^{1}$ Departments of Biological Chemistry and Neuroscience, Johns Hopkins School of Medicine, Baltimore, Maryland 21205, and ${ }^{2}$ Department of \\ Pharmacology, Jichi Medical School, Mimamikawachi, Tochigi 329-0498, Japan
}

\begin{abstract}
Transient receptor potential vanilloid 4 (TRPV4), a cation channel responsive to hypotonicity, can also be activated by warm temperatures. Moreover, TRPV4 ${ }^{-1-}$ mice reportedly exhibit deficits in inflammation-induced thermal hyperalgesia. However, it is unknown whether TRPV4 or related transient receptor potential channels account for warmth perception under injury-free conditions. We therefore investigated the contribution of TRPV4 to thermosensation and thermoregulation in vivo. On a thermal gradient, TRPV4 ${ }^{-1-}$ mice selected warmer floor temperatures than wild-type littermates. In addition, whereas wild-type mice failed to discriminate between floor temperatures of 30 and $34^{\circ} \mathrm{C}$, TRPV4 $4^{-1-}$ mice exhibited a strong preference for $34^{\circ} \mathrm{C}$. TRPV4 ${ }^{-1-}$ mice also exhibited prolonged withdrawal latencies during acute tail heating. TRPV $4^{-1-}$ and wild-type mice exhibited similar changes in behavior on a thermal gradient after paw inflammation. Circadian body temperature fluctuations and thermoregulation in a warm environment were also indistinguishable between genotypes. These results demonstrate that TRPV4 is required for normal thermal responsiveness in vivo.
\end{abstract}

Key words: TRPV4; thermosensation; warm; heat; temperature; pain

\section{Introduction}

Mammals monitor environmental temperature using specialized cutaneous warm- and cold-sensitive neurons, the firing rates of which change as a function of absolute skin temperature or acute temperature changes (Hensel, 1981). Insight into the possible mechanistic basis of these thermotransduction events has come from the identification of heat-gated ion channels of the transient receptor potential (TRP) family. TRP vanilloid 1 (TRPV1) is a nonselective cation channel that is highly expressed in nociceptive neurons and can be activated either by chemical agents such as capsaicin or by elevations in ambient temperature to $>42^{\circ} \mathrm{C}$ (Caterina and Julius, 2001). Accordingly, TRPV1-null mice exhibit defects in acute painful heat sensation and inflammationinduced thermal hyperalgesia (Caterina et al., 2000; Davis et al., 2000). TRPV3 (Peier et al., 2002; Smith et al., 2002; Xu et al., 2002) and TRPV4 (Liedtke et al., 2000; Strotmann et al., 2000; Wissenbach et al., 2000) are homologous channels that can be activated in vitro by warm temperatures, with thresholds of $\sim 32-$ $39^{\circ} \mathrm{C}$ (Peier et al., 2002; Smith et al., 2002; Xu et al., 2002) and $\sim 25-34^{\circ} \mathrm{C}$ (Guler et al., 2002; Watanabe et al., 2002a), respectively. TRPV4 can alternatively be activated by nonthermal stim-

Received Aug. 19, 2004; revised Dec. 23, 2004; accepted Dec. 23, 2004.

This work was supported by American Cancer Society Research Scholar Grant RSG-01-063-01-CSM and grants from The W. M. Keck Foundation, Searle Scholars Program, Arnold and Mabel Beckman Foundation, and Dainippon Pharmaceutical Company to M.J.C. We thank Isao Shimizu for development of the thermal selection assays, Juan Wang for technical assistance, and David Ginty, Craig Montell, Martin Koltzenburg, Pierre Coulombe, Cheryl Stucky, and members of the Caterina laboratory for helpful suggestions.

Correspondence should be addressed to Dr. Michael J. Caterina, Department of Biological Chemistry, Johns Hopkins School of Medicine, 408 Biophysics Building, 725 North Wolfe Street, Baltimore, MD 21205. E-mail: caterina@jhmi.edu.

DOI:10.1523/JNEUROSCI.4745.04.2005

Copyright $\odot 2005$ Society for Neuroscience $\quad$ 0270-6474/05/251304-07\$15.00/0 uli, including hypo-osmolarity (Liedtke et al., 2000; Strotmann et al., 2000; Wissenbach et al., 2000), certain synthetic phorbol esters, and 5',6'-epoxyeicosatrienoic acid (Watanabe et al., 2002b, 2003). Consistent with its thermosensitivity in vitro, TRPV4 protein has been detected in several potential thermosensory locations, including primary sensory neurons, skin keratinocytes, and the preoptic/anterior hypothalamus (Liedtke et al., 2000; Guler et al., 2002; Alessandri-Haber et al., 2003).

Several studies have suggested the potential importance of TRPV4 for osmosensitivity/mechanosensitivity. Intrathecal pretreatment with antisense TRPV4 oligonucleotides has been shown to reduce mechanical hyperalgesia resulting from intradermal injection of hypotonic solution after prostaglandin- or taxol-induced nociceptor sensitization (Alessandri-Haber et al., 2003, 2004). Furthermore, TRPV4 ${ }^{-1-}$ mice have been reported to exhibit reduced electrophysiological and behavioral responses to intense noxious mechanical stimuli but normal thresholds for mechanically evoked paw withdrawal (Liedtke and Friedman, 2003; Suzuki et al., 2003). Peripheral nerve recordings have suggested that there might be a decrease in warmth-evoked electrical activity in TRPV4 ${ }^{-1-}$ mice (Todaka et al., 2004). Moreover, we demonstrated that keratinocytes cultured from these animals lack the TRPV4-like warmth-activated currents observed in wildtype keratinocytes (Chung et al., 2004). In contrast, no changes in escape latency from heat stimuli were observed in either the hotplate (Suzuki et al., 2003; Todaka et al., 2004) or radiant pawheating (Liedtke and Friedman, 2003) assays. After subcutaneous injection of capsaicin or carrageenan, however, TRPV4 ${ }^{-/-}$mice showed longer escape latencies from a hot surface, relative to wild-type controls (Todaka et al., 2004). Thus, the precise contributions of TRPV4 to thermosensation and thermoregulation in vivo remain unclear. The main purpose of this study was there- 
fore to address whether TRPV4 is required for normal behavioral responsiveness to warmth in the absence of injury and to explore thermoregulation in $\mathrm{TRPV}^{-/-}$mice using telemetric monitoring.

\section{Materials and Methods}

Animals. TRPV4 knock-out mice (Suzuki et al., 2003) were backcrossed five generations onto a C57BL/6 background. Wild-type and TRPV4 $4^{-1-}$ animals were obtained by mating heterozygous TRPV4 ${ }^{+/-}$animals. Age-matched male mice 11-17 weeks of age were individually housed at least 1 week before behavioral assays. Ambient temperature was maintained at $25 \pm 1{ }^{\circ} \mathrm{C}$ with a light cycle from 8:00 A.M. to 8:00 P.M. All behavioral assays were performed between 9:00 A.M. and 7:00 P.M. A single cohort of animals was used in all experiments except those shown in Figure 3. Body weights were indistinguishable between genotypes (wild type, $25.78 \pm 0.94 \mathrm{~g}$; TRPV4 ${ }^{-1-}, 26.49 \pm 0.56 \mathrm{~g}$ ). C57BL/ 6 wildtype mice were obtained from Jackson Laboratories (Bar Harbor, ME). All experiments were conducted according to protocols approved by The Johns Hopkins Animal Care and Use Committee.

Thermal gradient assay. After $30 \mathrm{~min}$ acclimation in a Plexiglas box with its floor at room temperature $\left(24-26^{\circ} \mathrm{C}\right)$, an individual naive mouse was placed in a $170 \mathrm{~cm}$ (length) $\times 10 \mathrm{~cm}$ (width) $\times 16.5 \mathrm{~cm}$ (height) chamber with Plexiglas walls and an aluminum floor on which a temperature gradient was maintained along the long axis from 0.8 to $48.8^{\circ} \mathrm{C}$ using feedback-controlled resistive heaters (Heat wave; Dagan, Minneapolis, MN) and a circulating water bath. The stability of the gradient was monitored several times each day using a thermistor (SST-1; Physitemp, Clifton, NJ). The chamber was uniformly illuminated with diffuse fluorescent light, and the sides were masked with cardboard to mask any positional cues. The presence time and position of the mouse within the gradient was then monitored at $10 \mathrm{~Hz}$ over $120 \mathrm{~min}$, using a series of 64 infrared beams and activity tracking software (OptiMax; Columbus Instruments, Columbus, $\mathrm{OH}$ ). Three mice were tested each day. The weighted average of occupied temperature $\left(T_{\text {avg }}\right)$ was calculated using the following equation: $T_{\text {avg }}=[\Sigma$ (percentage of time at a given temperature $\times$ temperature $)] / 100 \%$. Peak "preferred" temperature $\left(T_{\text {peak }}\right)$ was defined as the single temperature at which each mouse spent the maximum time.

For peripheral inflammation experiments, mice were tested once in the thermal gradient assay. Approximately 1 week later, mice were briefly anesthetized with methoxyflurane, and $50 \mu \mathrm{l}$ of Complete Freund's adjuvant (CFA) (Sigma, St. Louis, MO) was injected subcutaneously into the plantar surface of one hindpaw using a Hamilton (Hamilton, Reno, $\mathrm{NV}$ ) syringe and 30 gauge needle. The following day, the thermal gradient assay was repeated, and paw diameter was measured using a thickness gauge (Mitutoyo, Kanagawa, Japan). In this assay and in the twotemperature selection assay described below, to minimize the influence of temporally changing environmental variables and circadian rhythm on behavioral comparison, mice of the two genotypes were assayed in alternating manner. The individual who placed the mice in the behavioral apparatus was therefore aware of mouse genotype, but all behavioral data were recorded by computer with the operator absent from the room.

Two-temperature selection assay. A mouse was individually acclimated for $60 \mathrm{~min}$ in a Plexiglas box with its floor at room temperature (24$26^{\circ} \mathrm{C}$ ) and then placed in a $31 \mathrm{~cm}$ (length) $\times 21 \mathrm{~cm}$ (width) $\times 21 \mathrm{~cm}$ (height) chamber. The chamber floor consisted of two temperaturecontrolled aluminum blocks thermally isolated from one another by plastic spacers. Mouse position was monitored for $60 \mathrm{~min}$ as described above. Seven to eight mice were tested each day, and the chamber was cleaned between mice. The position of the two temperatures was rearranged daily to exclude possible contributions from spatial preference. In control experiments in which a single floor temperature was used, wildtype mice exhibited a uniform distribution between the two blocks.

Tail-immersion assay. As described previously (Caterina et al., 2000), after 30 min acclimation in a Plexiglas box, the tail of a gently restrained mouse was immersed in a water bath set at a single temperature from 45 to $50^{\circ} \mathrm{C}$, and time to tail flick was recorded. This assay was performed with the investigator blinded to genotype. Latencies at a given tempera- ture were recorded during three trials separated by $\geq 20 \mathrm{~min}$ and averaged. Mice were allowed to rest $\geq 3 \mathrm{~d}$ between temperatures. Cutoff time was $45 \mathrm{~s}$, after which the tail was removed from the bath regardless of response.

Core body temperature measurement. Animals were anesthetized with ketamine $(80 \mathrm{mg} / \mathrm{kg}$, i.p.) and xylazine $(8 \mathrm{mg} / \mathrm{kg}$, i.p.). Abdominal fur was shaved, and skin was cleansed with alcohol. A sterilized telemetric temperature/activity probe (PDT-4000; Minimitter, Bend, OR) was inserted into the peritoneal cavity via a $1 \mathrm{~cm}$ midline incision and sutured to the abdominal musculature. Abdominal muscle and skin layers were sutured separately. Buprenorphine $(0.5 \mathrm{mg} / \mathrm{kg}$, s.c. $)$ was injected immediately after surgery and again the following day. All transmitters were calibrated before surgery. Mice were allowed to recover $\geq 6 \mathrm{~d}$ before experiments. For circadian core body temperature $\left(T_{\mathrm{c}}\right)$ measurement, individually caged mice were acclimated $2 \mathrm{~d}$ in a ventilated stability chamber (Powers Scientific, Pipersville, PA) maintained at $25^{\circ} \mathrm{C} / 50 \%$ humidity, with a light cycle from 8:30 A.M. to 8:30 P.M. and with food and water available ad libitum. $T_{\mathrm{c}}$ was then monitored continuously at 5 min intervals over $3 \mathrm{~d}$ using telemetric radio receiver platforms and VitalView software (Minimitter). For ambient warmth exposure, $T_{\mathrm{c}}$ was monitored every minute over a $6 \mathrm{~h}$ period, beginning at 10:30 A.M., with the chamber at $25^{\circ} \mathrm{C}$ and the water bottle removed from the cage. The following day, the water bottle was again removed from the cage and after a $1 \mathrm{~h}$ baseline period, the temperature of the chamber was increased to $35^{\circ} \mathrm{C}$ within $11 \mathrm{~min}$ and held for a total of $2 \mathrm{~h}$, followed by return to $25^{\circ} \mathrm{C}$ within $10 \mathrm{~min}$.

Statistical analyses. Data are expressed as mean \pm SEM $(n=$ number of animals). Statistical comparisons were performed using two-way ANOVA with Bonferroni correction, two-tailed unpaired Student's $t$ test, or Mann-Whitney $U$ test, as indicated.

\section{Results}

\section{TRPV4 ${ }^{-1-}$ mice exhibit altered thermal selection behavior}

To test the potential role of TRPV4 in thermosensation in vivo, we subjected TRPV4 ${ }^{-1-}$ mice and wild-type littermates to two assays of thermal selection behavior. In the thermal gradient assay, an individual mouse was placed in a $170 \times 10 \mathrm{~cm}$ chamber with a floor temperature gradient ranging from 0.8 to $48.8^{\circ} \mathrm{C}$. Over $2 \mathrm{~h}$, mouse position along the gradient was monitored with infrared beam photodetectors. The proportion of time spent at each floor temperature was then calculated and compared between groups. We previously used this assay to demonstrate that mice lacking the ATP-gated ion channel, $\mathrm{P} 2 \mathrm{X}_{3}$, occupy a more narrow temperature range than wild-type controls, despite similar peak preferred temperatures (I. Shimizu and M. Caterina, unpublished observation). Typically, during the initial hour in the gradient, mice spent considerable time exploring their new environment. Over time, however, they settled within a narrow range of temperatures (Fig. 1A, top panels). We therefore plotted separately, for each mouse, the time spent at different temperatures during the first and second hours of the assay (Fig. $1 A$, middle and bottom panels). By averaging occupancy at each temperature for all mice of a given genotype, we obtained an overall population distribution (Fig. 1B). Comparison of wild-type and TRPV4 ${ }^{-1-}$ mice revealed that during the first hour, their distributions within the gradient were similar but with a slight preference among TRPV4 ${ }^{-1-}$ mice for warmer temperatures. Over the ensuing 60 min, this differential distribution became more obvious, with a clear "rightward" shift in the knock-outs. Still, the distribution of the TRPV $4^{-l-}$ mice contained a steep shoulder above $\sim 36^{\circ} \mathrm{C}$, suggesting a TRPV4-independent barrier to an additional shift.

To compare these distributions with greater temporal resolution, we calculated the weighted average of occupied temperature $\left(T_{\text {avg }}\right)$ and the peak preferred temperature $\left(T_{\text {peak }}\right)$ for each mouse over 10 min intervals (Fig. 1C). Although both parameters were quite similar between genotypes during the initial $50 \mathrm{~min}$ of the 


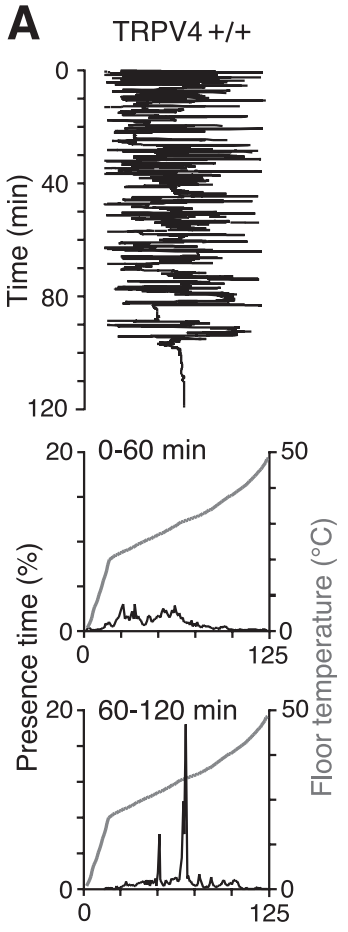

Position in gradient
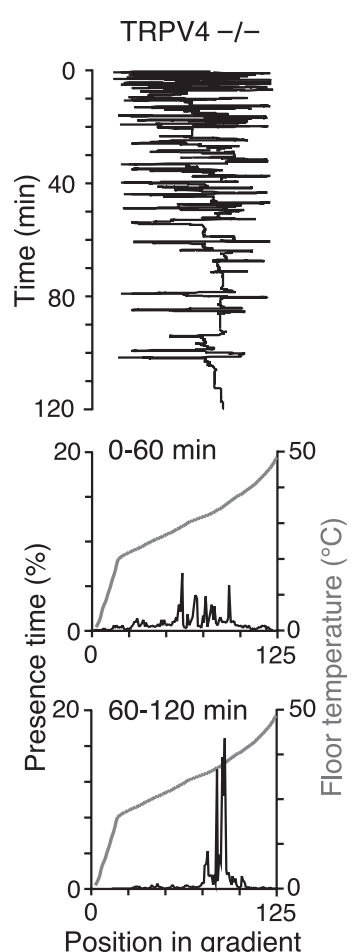

Position in gradient
B
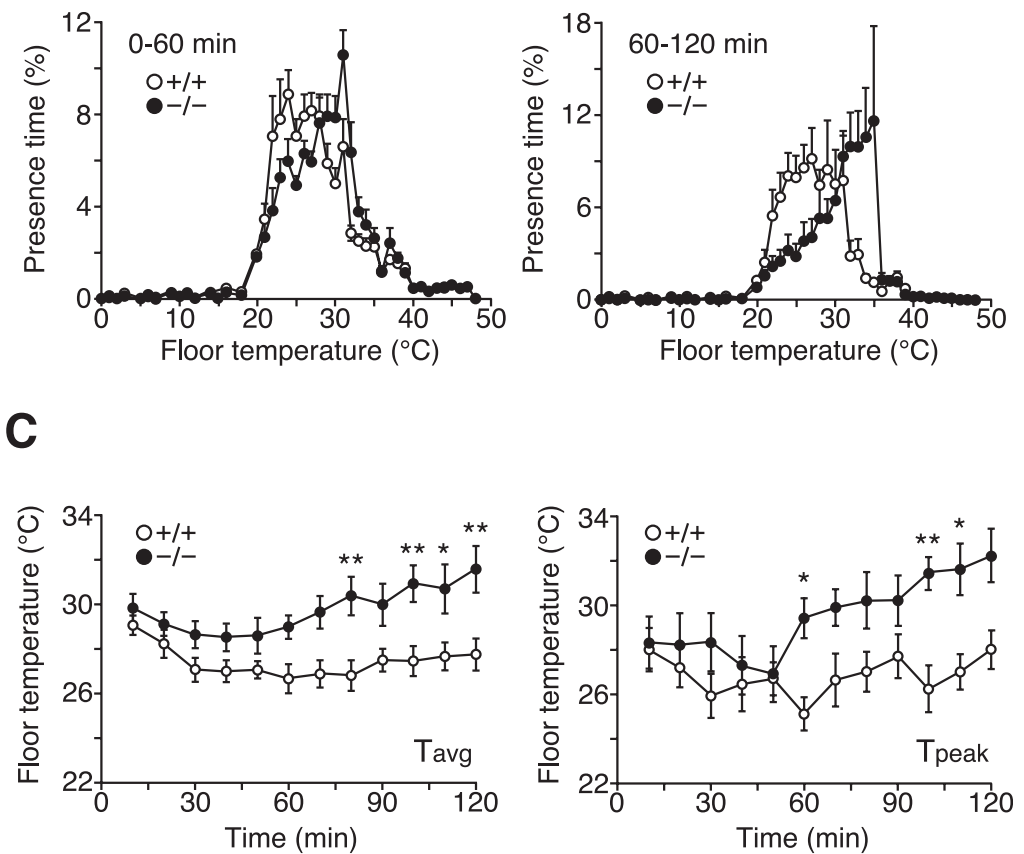

Figure 1. TRPV4 ${ }^{-/-}$mice exhibit increased occupancy of warm temperatures in a thermal gradient. $A$, Top, Position of representative individual TRPV4 ${ }^{+/+}$and TRPV4 ${ }^{-/-}$mice $(1$ mouse per trace) in a $0.8-48.8^{\circ} \mathrm{C}$ thermal gradient over a $2 \mathrm{~h}$ period. Middle, bottom, Gray traces indicate temperature as a function of position within the gradient. The black traces indicate the percentage of time spent at a given temperature by these same two mice during the first (middle) or last (bottom) 60 min of the assay. $B$, Mean presence times, plotted as a function of temperature, for TRPV $4^{+1+}$ (open circles) and TRPV4 ${ }^{-1-}$ (filled circles) mice during the initial (left) or final (right) 60 min of the assay $\left(n=10\right.$ per genotype). $C$, Weighted average of occupied temperatures $\left(T_{\text {avg }}\right.$; left) and peak occupied temperatures $\left(T_{\text {peak }} ;\right.$ right) calculated for TRPV4 ${ }^{+1+}$ (open circles) and TRPV $4^{-1-}$ (filled circles) mice at each 10 min interval during the assay (mean \pm SEM; ${ }^{*} p<0.05$; ${ }^{* *} p<0.01$; two-way ANOVA with Bonferroni correction; $n=10$ per genotype).

assay, they began to diverge at later times. Two-way ANOVA revealed a significant main effect of genotype on both parameters $(p<0.0001)$, with pairwise differences in $T_{\text {avg }}$ detectable at four of the last seven 10 min intervals and differences in $T_{\text {peak }}$ detectable in three of the last seven intervals (following Bonferroni correction for repeated measures). Over the last $60 \mathrm{~min}, T_{\mathrm{avg}}$ was $28.1 \pm 0.6$ versus $32.0 \pm 0.6^{\circ} \mathrm{C}$ for wild-type and TRPV4 ${ }^{-1-}$ mice, respectively ( $p<0.01$; unpaired Student's $t$ test; $n=10$ per genotype), and $T_{\text {peak }}$ was $28.6 \pm 0.8$ versus $34.0 \pm 0.6^{\circ} \mathrm{C}(p<$ $0.01 ; n=10$ per genotype).

To exclude the possibility that this difference in distribution was a result of the influence of noxious temperatures at the extremes of the gradient and to determine whether TRPV4 ${ }^{-1-}$ mice were capable of distinguishing two temperatures normally considered innocuous, an alternative thermal selection assay was performed. In this assay, a mouse was placed in a rectangular chamber of which the floor consisted of two adjacent temperature-controlled aluminum surfaces maintained at different temperatures. Mouse position was continuously monitored for $60 \mathrm{~min}$, and occupancy in each region was calculated over 10 min intervals. When the floor temperatures were set at 30 and $34^{\circ} \mathrm{C}$, respectively, wild-type mice exhibited little preference for one region over the other at any of the six intervals (Fig. $2 A$ ). In contrast, whereas TRPV $4^{-1-}$ mice exhibited no apparent preference at early times, the proportion of time spent at $34^{\circ} \mathrm{C}$ gradually increased, becoming significantly greater than that of wild-type mice at all intervals after $30 \mathrm{~min}$. Within the final interval, TRPV $4^{-1-}$ mice spent $90.7 \pm 7.5 \%$ of their time at $34^{\circ} \mathrm{C}$, compared with $55.3 \pm 10.8 \%$ for wild type $(p<0.05$; two-way ANOVA; $n=10$ per genotype). This result is consistent with that of the thermal gradient assay, over the same temperature range. When selecting between 34 and $36^{\circ} \mathrm{C}$, wild-type and TRPV4 $4^{-1-}$ mice exhibited a similar, strong preference for 34 over $36^{\circ} \mathrm{C}$ at all time intervals (Fig. 2 B). Thus, TRPV4 ${ }^{-1-}$ mice exhibit a robust alteration in thermal preference toward warmer temperatures but appear to retain significant residual heat avoidance capacity.

We next explored the effect of peripheral inflammation on thermal preference in wild-type and TRPV4 ${ }^{-1-}$ mice (Fig. 3). One week after initial examination in the thermal gradient assay, mice received an intraplantar injection of CFA $(50 \mu \mathrm{l})$ in their right hindpaw. The following day, the thermal gradient assay was repeated. As in Figure 1, during the initial $60 \mathrm{~min}$ of the assay period, naive wild-type and TRPV4 ${ }^{-1-}$ mice exhibited similar broad occupancy profiles in the thermal gradient apparatus (Fig. $3 A$, left). During the ensuing 60 min period, however, the profile of TRPV4 ${ }^{-1-}$ mice was again shifted toward warmer temperatures than that of wild-type controls (Fig. $3 A$, right) $\left(T_{\mathrm{avg}}, p<\right.$ 0.0001 by two-way ANOVA; wild type, $n=7$; TRPV4 $\left.{ }^{-\prime-}, n=9\right)$. One day after CFA injection, nearly identical degrees of paw inflammation were observed in wild-type and TRPV4 ${ }^{-I-}$ mice (wild-type paw diameter: control, $1.6 \pm 0.0 \mathrm{~mm}$; CFA, $2.8 \pm 0.1$ $\mathrm{mm} ; p<10^{-6} ; n=7$; TRPV4 ${ }^{-1-}$ : control, $1.6 \pm 0.0 \mathrm{~mm}$; CFA, $2.8 \pm 0.1 \mathrm{~mm} ; p<10^{-6}$, unpaired Student's $t$ test; $n=9$ ) (Fig. $3 B$, inset). In addition, CFA injection produced changes in thermal selection that were evident in two ways. First, both wild-type and TRPV4 ${ }^{-1-}$ mice selected a relatively more narrow range of floor temperatures within the initial $60 \mathrm{~min}$ of the assay (Fig. 3B, left) than they had before injection. In fact, these distributions closely resembled those adopted during the 60-120 min period of the preinjection assay. Second, during the 60-120 min period 
A

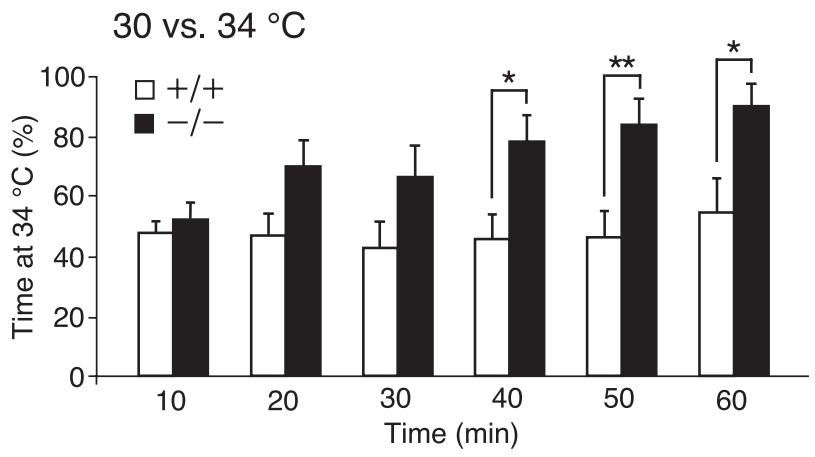

B

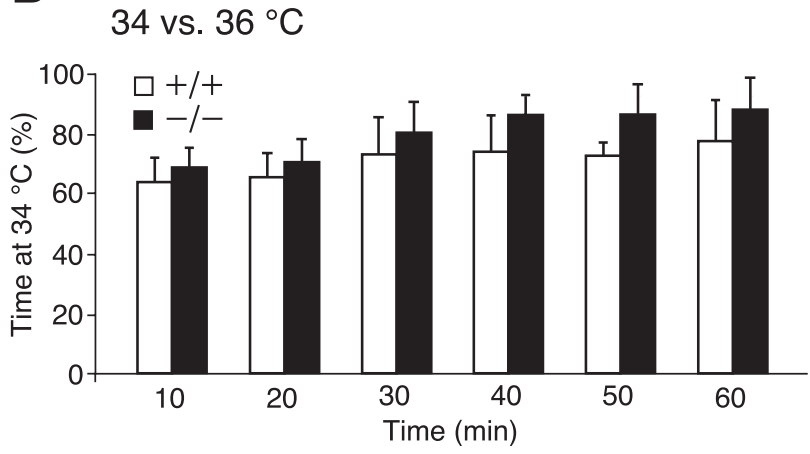

Figure 2. TRPV $4^{-1-}$ mice exhibit altered thermal preference in a two-temperature selection assay. $A$, Percentage of time spent at $34^{\circ} \mathrm{C}$ during each $10 \mathrm{~min}$ interval of a 60 min test period when given a choice between 30 and $34^{\circ} \mathrm{C}$ floor temperatures. $B$, Same as $A$ but with floor temperatures at 34 and $36^{\circ} \mathrm{C}$. TRPV $4^{+/+}$mice, Open bars; TRPV $4^{-1-}$ mice, filled bars. Mean \pm SEM; ${ }^{*} p<0.05 ;{ }^{* *} p<0.01$; two-way ANOVA with Bonferroni correction; $n=10$ per genotype.

(Fig. 3B, right), CFA-injected mice exhibited an even more narrow range of thermal occupancy, between 30 and $35^{\circ} \mathrm{C}$, with little occupancy in the $20-30^{\circ} \mathrm{C}$ range and no obvious change in their avoidance of elevated temperatures. As a consequence, the difference in thermal selection behavior between wild-type and TRPV4 ${ }^{-1-}$ mice was virtually ablated. An independent group of wild-type mice injected with CFA exhibited similar changes in thermal preference, whereas saline-injected control mice did not (data not shown). To exclude the possibility that repeated assay of the same animals accounted for the apparent effects of CFA, we assayed a group of wild-type mice in the thermal gradient in two trials separated by $\sim 1$ week. In these animals, no obvious changes in overall distribution in the thermal gradient were observed between the first and second trials in either $60 \mathrm{~min}$ period (Fig. $3 C$ ). These results indicate that CFA-induced inflammation produces similar thermal preference changes in wild-type and TRPV4 ${ }^{-I-}$ mice.

\section{TRPV4 ${ }^{-/-}$mice exhibit reduced acute avoidance of moderately hot temperature}

One limitation of the thermal selection assays described above is that they depend on behaviors that become evident only over many minutes. In addition, it is difficult to distinguish, based solely on these assays, whether a mouse is choosing a "desirable" environment or avoiding an aversive one. To address these issues, we next performed the tail-immersion assay (Mogil et al., 1999). Both wild-type and TRPV4 ${ }^{-1-}$ mice withdrew their tails after tail immersion into heated water baths, with progressively shorter latencies at higher temperatures (Fig. 4). At all temperatures between 47 and $50^{\circ} \mathrm{C}$, although TRPV4 ${ }^{-1-}$ mice exhibited a tendency toward longer latencies, no significant differences from wild type were observed. In contrast, at 45 and $46^{\circ} \mathrm{C}$, TRPV $4^{-1-}$ mice exhibited significantly longer withdrawal latencies than wild-type mice $\left(45^{\circ} \mathrm{C}\right.$ : wild type, $28.0 \pm 3.0 \mathrm{~s}$; $\mathrm{TRPV}^{-/-}, 38.1 \pm$ $2.2 \mathrm{~s} ; p<0.05 ; 46^{\circ} \mathrm{C}$ : wild type, $32.8 \pm 3.4 \mathrm{~s}$; $\mathrm{TRPV}^{-/-}, 41.4 \pm$ $1.6 \mathrm{~s} ; p<0.05$; Mann-Whitney $U$ test; $n=10$ per genotype). This result indicates that TRPV4 ${ }^{-1-}$ mice exhibit a small but significant deficit in thermal responsiveness during acute challenge with moderate heat.

TRPV4 ${ }^{-/-}$mice exhibit normal circadian body temperatures and thermoregulatory responses to a warm environment

The behavioral alterations in thermal responsiveness exhibited by TRPV4 ${ }^{-1-}$ mice might reflect a requirement for TRPV4 in peripheral thermosensation. However, TRPV4 is expressed in hypothalamic regions known to integrate local and peripheral temperature changes (Liedtke et al., 2000; Guler et al., 2002; Liedtke and Friedman, 2003). Therefore, another possibility is that central thermoregulatory mechanisms (and, consequently, behavioral thermoregulation) are altered in these mice. To evaluate this possibility, we surgically implanted telemetric body temperature probes into the peritoneal cavities of wild-type and TRPV4 $4^{-1-}$ mice and continuously monitored core body temperature $\left(T_{\mathrm{c}}\right)$ over several days. At an ambient temperature of $25^{\circ} \mathrm{C}$, the circadian pattern of $T_{\mathrm{c}}$ in TRPV4 $4^{-1-}$ mice was indistinguishable from that of wild-type controls (Fig. $5 A$ ). In both genotypes, $T_{\mathrm{c}}$ was lower during the light period (8:30 A.M. to 8:30 P.M.; wild-type, $35.9 \pm 0.2^{\circ} \mathrm{C}$; $\mathrm{TRPV}^{-/-}, 35.9 \pm 1.0^{\circ} \mathrm{C} ; n=8$ per genotype $)$ and higher during the dark period (8:30 P.M. to 8:30 A.M.; wild-type, $37.2 \pm 0.1^{\circ} \mathrm{C}$, vs TRPV $\left.4^{-1-}, 37.2 \pm 0.1^{\circ} \mathrm{C}\right)$. Activity measurements also revealed no differences between genotypes in either the light or dark periods (data not shown). We next examined whether $T_{\mathrm{c}}$ responses to an acute change in environmental temperature might be altered in mice lacking TRPV4 (Fig. 5B). After an abrupt change in ambient temperature from 25 to $35^{\circ} \mathrm{C}$, wildtype and TRPV4 ${ }^{-1-}$ mice exhibited virtually identical increases in $T_{\mathrm{c}}$ that reversed to several degrees below baseline when the environmental temperature was abruptly returned to $25^{\circ} \mathrm{C}$. No differences between genotypes in absolute $T_{c}$ were observed in these experiments (data not shown). These results suggest that TRPV4 is not essential for normal thermoregulation at normothermic or moderately hyperthermic environmental temperatures.

\section{Discussion}

The identification of TRPV4 as a warmth-gated nonselective cation channel has led to speculation that this molecule might act as a warmth sensor in vivo (Guler et al., 2002). However, until now, definitive support for such a physiological role has been lacking. One study reported that, after capsaicin- or carrageenan-evoked inflammation, TRPV4 ${ }^{-1-}$ mice failed to exhibit the same reduction in hot-plate escape latency as wild-type mice (Todaka et al., 2004). The same study suggested that there was a reduction in the activity of warmth-sensitive peripheral nerve fibers in these mice, even in the uninjured state. However, the unexpectedly high prevalence of apparently warmth-sensitive units in that study contradicts the reported paucity of classically defined warm receptors in the rodent limb (Leem et al., 1993), making these results difficult to interpret. Moreover, neither those investigators nor another group assaying an independent line of TRPV4 ${ }^{-1-}$ mice observed differences in baseline behavioral responses in the hot-plate (Suzuki et al., 2003; Todaka et al., 2004) 
or radiant paw-heating (Liedtke and Friedman, 2003) assays. Thus, it has remained unresolved whether TRPV4 contributes to thermosensation in the absence of injury. In the present study, we used behavioral assays based on innocuous thermal selection and thermal avoidance to demonstrate that the absence of TRPV4 results in a shift in selection behavior toward warmer temperatures and a prolonged latency of tail withdrawal from moderately hot temperatures.

It is not unusual for genetically determined differences in thermosensory function to appear in one behavioral assay and not another. For example, the rank-order sensitivities among inbred mouse strains differ between the hot-plate and radiant paw-heating assays as well as the tailimmersion assay (Mogil et al., 1999). Moreover, disruption of the gene encoding TRPV1 results in a more robust increase in tail-immersion and hot-plate latencies than radiant paw-heating latency (Caterina et al., 2000). Several differences among the behavioral assays used in these studies may account for the apparent discrepancies. These assays involve anatomically distinct tissues, use different heat sources that alter skin temperature with different kinetics and geometries, and operate over temperature ranges that overlap only partially, with different thresholds for responsiveness even in wild-type mice. Furthermore, the readouts and time courses of these assays differ considerably. Thus, the behavioral results we report here are not inconsistent with previous studies.

The phenotypic changes observed among TRPV4 ${ }^{-1-}$ mice in this study all involve a shift toward occupancy or tolerance of higher temperatures. However, it is unclear to what extent these changes reflect a role for TRPV4 in nociceptive thermal avoidance behavior versus selection of desirable temperatures, based on the balance of innocuous warm and cold thermal inputs to the brain. The increased latencies observed in TRPV4 ${ }^{-1-}$ mice in the tail-immersion assay support some contribution of TRPV4 to heat nociception. However, the thermal selection assays that we used are probably influenced by both nociceptive and nonnociceptive pathways and may involve behavioral thermoregulatory responses [i.e., attraction toward a warm surface in the context of an air temperature $\left(25^{\circ} \mathrm{C}\right)$ that is below thermoneutrality] (Gordon, 1993). A contribution from non-nociceptive pathways is suggested by the fact that, in both thermal selection assays, wild-type and TRPV4 ${ }^{-1-}$ mice occupy similar temperatures at early time points, with TRPV4 ${ }^{-/-}$mice shifting toward warmer temperatures, rather than wild-type mice, over time. A nonnociceptive component is also suggested by the relatively innocuous temperature range over which these differences are observed. Thus, TRPV4 may contribute to nociceptive and nonnociceptive thermal inputs to the CNS.

Given these results, it is interesting to consider the in vitro thermal response profiles of the four known heat-sensitive TRPV

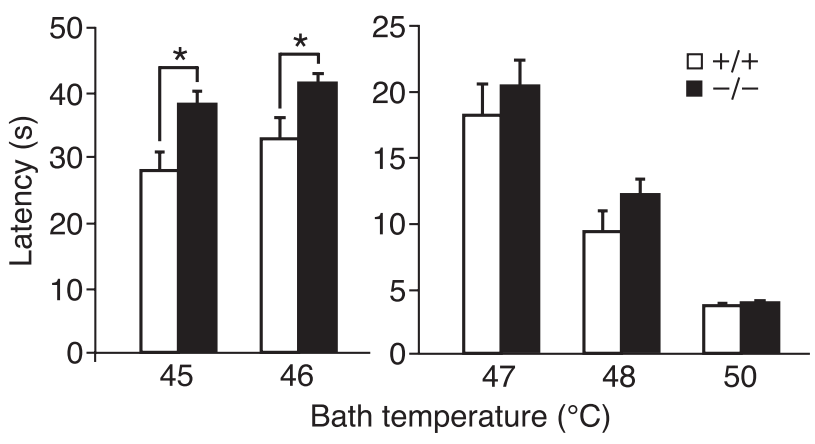

Figure 4. TRPV4 ${ }^{-1-}$ mice exhibit prolonged tail-withdrawal latency at moderately hot temperatures. Tail-withdrawal latencies after immersion into a water bath at the indicated temperatures were compared between TRPV $4^{+/+}$(open bars) and TRPV $4^{-1-}$ (filled bars) mice (mean $\pm S E M ;{ }^{*} p<0.05$; Mann-Whitney $U$ test; $n=10$ per genotype).

channels. TRPV4 becomes detectably activated beginning at 25$34^{\circ} \mathrm{C}$, depending on the assay conditions (Guler et al., 2002; Watanabe et al., 2002a). TRPV3, in contrast, exhibits an apparently higher activation threshold $\left(\sim 32-39^{\circ} \mathrm{C}\right)$ (Peier et al., 2002; Smith et al., 2002; Xu et al., 2002), whereas TRPV $1\left(42^{\circ} \mathrm{C}\right)$ (Caterina et 
A

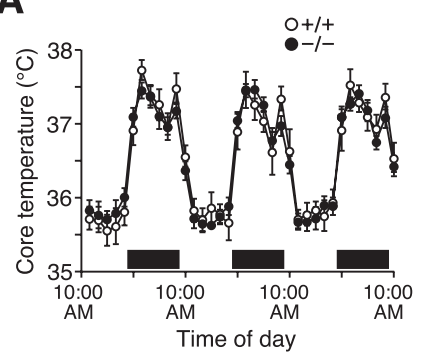

B

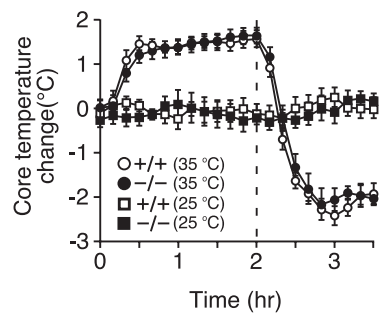

Figure 5. TRPV4 ${ }^{-1-}$ mice exhibit normal body temperature regulation. $A$, Circadian variation in core body temperature over a $3 \mathrm{~d}$ period in TRPV $4^{+/+}$(open circles) and TRPV $4^{-1-}$ (filled circles) mice. Horizontal bars indicate the dark period. Data (mean $\pm \mathrm{SEM} ; n=8$ per genotype) were averaged at $2 \mathrm{~h}$ intervals. $B$, Change in core body temperature recorded at a uniform temperature of $25^{\circ} \mathrm{C}$ (squares) or during an acute increase in ambient temperature to $35^{\circ} \mathrm{C}$ (circles). TRPV $4^{+1+}$ mice, Open symbols; TRPV4 ${ }^{-1-}$ mice, filled symbols. The chamber temperature was raised at time $=0$. Dotted line, Return from 35 to $25^{\circ} \mathrm{C}$. Data (mean $\pm \mathrm{SEM}$; $n=8$ per genotype) were sampled at 10 min intervals.

al., 1997) and TRPV2 $\left(52^{\circ} \mathrm{C}\right)$ (Caterina et al., 1999) are activated at even higher temperatures. This progression of thermal response profiles suggests that these channels are successively recruited to mediate thermosensation and thermal nociception at increasing temperatures. Our thermal selection and thermal avoidance data fit this model well. In mice lacking TRPV4, thermal selection assays revealed a persistent strong avoidance of temperatures $\geq 36^{\circ} \mathrm{C}$, whereas the tail-immersion latencies exhibited by these mice were statistically indistinguishable from wild type at $\geq 47^{\circ} \mathrm{C}$. These temperatures may define where the thermosensory relevance of TRPV4 ends and where that of other channels begins in a given assay. Mice lacking TRPV1 show normal behavior in the thermal gradient assay (Shimizu and Caterina, unpublished observation) and exhibit increases in tailimmersion latency that become robust only at temperatures $\geq 50^{\circ} \mathrm{C}$ (Caterina et al., 2000). These findings leave TRPV3 as the best candidate for thermosensory mediator at intermediate temperatures. Mice lacking TRPV3 alone or in combination with the other heatsensitive channels may allow this possibility to be tested.

After the induction of peripheral inflammation by CFA, both wild-type and TRPV4 ${ }^{-1-}$ mice exhibited more restricted ranges of occupancy on the thermal gradient than they did before CFA injection. Surprisingly, this change appeared to reflect less occupancy at modestly cold temperatures, without enhanced avoidance of warm temperatures. Heat hyperalgesia is a well recognized consequence of inflammatory and neuropathic pain states, including CFA-induced inflammation (Iadarola et al., 1988). In contrast, cold allodynia has been more often associated with neuropathic pain (Choi et al., 1994). However, there have been some reports of cold allodynia after CFA injection into the sciatic nerve (Eliav et al., 1999) or rat tibio-tarsal joint (Takahashi et al., 2003). Additional studies will be required to determine whether cold allodynia or some other phenomenon accounts for our results. Nevertheless, the thermal gradient assay appears to be ill-suited for evaluating inflammatory heat hyperalgesia and, therefore, cannot tell us whether TRPV4 participates in this process.

Despite the expression of TRPV4 in thermosensitive regions of the hypothalamus, we observed no abnormalities in basal core body temperature, circadian body temperature fluctuation, or elevation of core temperature induced by environmental warmth. We also observed no differences in body temperature between wild-type and TRPV4 ${ }^{-1-}$ mice during the twotemperature selection assay $(\mathrm{H}$. Lee and M. Caterina, unpub-

lished observation). These findings argue against a primary hypothalamic defect as the cause of the behavioral changes reported in this study. They also are consistent with a previous study in which normal rectal temperatures were measured in TRPV4 ${ }^{-1-}$ mice at baseline and after acute cold exposure (Liedtke and Friedman, 2003). Still, we cannot exclude more subtle thermoregulatory abnormalities or rule out the possibility that acute TRPV4 antagonism might produce measurable thermoregulatory effects.

What cell type(s) is most relevant to TRPV4-dependent thermosensation in vivo? One possibility is that TRPV4 is required for normal warmth sensation by peripheral sensory neurons. Although TRPV4 protein appears to be expressed in sensory neurons (Alessandri-Haber et al., 2003), this expression level is apparently quite low (Delany et al., 2001; Guler et al., 2002). Furthermore, a clear functional demonstration of warmthevoked (as opposed to noxious heat-evoked) responses in isolated sensory neurons has not been reported, even in a situation in which potentially masking TRPV1-mediated heat responses are absent (Caterina et al., 2000). In contrast, skin keratinocytes, to which many cutaneous sensory neurons project, robustly express TRPV4. These cells also exhibit warmth-evoked electrophysiological currents that we found to be lost in keratinocytes derived from TRPV4 ${ }^{-1-}$ mice (Guler et al., 2002; Chung et al., 2003 , 2004). Thus, reduced thermosensory communication between keratinocytes and sensory afferents in the context of TRPV4 gene disruption offers one plausible explanation for our behavioral findings. TRPV4 expression has also been reported in endothelial cells, sweat glands, and sympathetic afferents, all locations in which it could conceivably participate in local thermoregulatory responses to warmth (Delany et al., 2001; Guler et al., 2002; Watanabe et al., 2002a). The definitive in vivo determination of the relevant cell type might therefore be best achieved by characterizing thermosensation and thermoregulation in mice with tissue-specific loss or gain of TRPV4 function.

\section{References}

Alessandri-Haber N, Yeh JJ, Boyd AE, Parada CA, Chen X, Reichling DB, Levine JD (2003) Hypotonicity induces TRPV4-mediated nociception in rat. Neuron 39:497-511.

Alessandri-Haber N, Dina OA, Yeh JJ, Parada CA, Reichling DB, Levine JD (2004) Transient receptor potential vanilloid 4 is essential in chemotherapyinduced neuropathic pain in the rat. J Neurosci 24:4444-4452.

Caterina MJ, Julius D (2001) The vanilloid receptor: a molecular gateway to the pain pathway. Annu Rev Neurosci 24:487-517.

Caterina MJ, Schumacher MA, Tominaga M, Rosen TA, Levine JD, Julius D (1997) The capsaicin receptor: a heat-activated ion channel in the pain pathway. Nature 389:816-824.

Caterina MJ, Rosen TA, Tominaga M, Brake AJ, Julius D (1999) A capsaicin receptor homologue with a high threshold for noxious heat. Nature 398:436-441.

Caterina MJ, Leffler A, Malmberg AB, Martin WJ, Trafton J, Petersen-Zeitz KR, Koltzenburg M, Basbaum AI, Julius D (2000) Impaired nociception and pain sensation in mice lacking the capsaicin receptor. Science 288:306-313.

Choi Y, Yoon YW, Na HS, Kim SH, Chung JM (1994) Behavioral signs of ongoing pain and cold allodynia in a rat model of neuropathic pain. Pain 59:369-376.

Chung MK, Lee H, Caterina MJ (2003) Warm temperatures activate TRPV4 in mouse 308 keratinocytes. J Biol Chem 278:32037-32046.

Chung MK, Lee H, Mizuno A, Suzuki M, Caterina MJ (2004) TRPV3 and TRPV4 mediate warmth-evoked currents in primary mouse keratinocytes. J Biol Chem 279:21569-21575.

Davis JB, Gray J, Gunthorpe MJ, Hatcher JP, Davey PT, Overend P, Harries MH, Latcham J, Clapham C, Atkinson K, Hughes SA, Rance K, Grau E, Harper AJ, Pugh PL, Rogers DC, Bingham S, Randall A, Sheardown SA (2000) Vanilloid receptor-1 is essential for inflammatory thermal hyperalgesia. Nature 405:183-187. 
Delany NS, Hurle M, Facer P, Alnadaf T, Plumpton C, Kinghorn I, See CG, Costigan M, Anand P, Woolf CJ, Crowther D, Sanseau P, Tate SN (2001) Identification and characterization of a novel human vanilloid receptorlike protein, VRL-2. Physiol Genomics 4:165-174.

Eliav E, Herzberg U, Ruda MA, Bennett GJ (1999) Neuropathic pain from an experimental neuritis of the rat sciatic nerve. Pain 83:169-182.

Gordon CJ (1993) Temperature regulation in laboratory rodents, pp 102106. New York: Cambridge UP.

Guler AD, Lee H, Iida T, Shimizu I, Tominaga M, Caterina M (2002) Heatevoked activation of the ion channel, TRPV4. J Neurosci 22:6408-6414.

Hensel H (1981) Thermoreception and temperature regulation, pp 33-63. London: Academic.

Iadarola MJ, Brady LS, Draisci G, Dubner R (1988) Enhancement of dynorphin gene expression in spinal cord following experimental inflammation: stimulus specificity, behavioral parameters and opioid receptor binding. Pain 35:313-326.

Leem JW, Willis WD, Chung JM (1993) Cutaneous sensory receptors in the rat foot. J Neurophysiol 69:1684-1699.

Liedtke W, Friedman JM (2003) Abnormal osmotic regulation in trpv4-/mice. Proc Natl Acad Sci USA 100:13698-13703.

Liedtke W, Choe Y, Marti-Renom MA, Bell AM, Denis CS, Sali A, Hudspeth AJ, Friedman JM, Heller S (2000) Vanilloid receptor-related osmotically activated channel (VR-OAC), a candidate vertebrate osmoreceptor. Cell 103:525-535.

Mogil J, Wilson SG, Bon K, Lee SE, Chung K, Raber P, Pieper JO, Hain HS, Belknap JK, Hubert L, Elmer GI, Chung JM, Devor M (1999) Heritability of nociception I: responses of 11 inbred mouse strains on 12 measures of nociception. Pain 80:67-82.

Peier AM, Reeve AJ, Andersson DA, Moqrich A, Earley TJ, Hergarden AC, Story GM, Colley S, Hogenesch JB, McIntyre P, Bevan S, Patapoutian A (2002) A heat-sensitive TRP channel expressed in keratinocytes. Science 296:2046-2049.
Smith GD, Gunthorpe MJ, Kelsell RE, Hayes PD, Reilly P, Facer P, Wright JE, Jerman JC, Walhin JP, Ooi L, Egerton J, Charles KJ, Smart D, Randall AD, Anand P, Davis JB (2002) TRPV3 is a temperature-sensitive vanilloid receptor-like protein. Nature 418:186-190.

Strotmann R, Harteneck C, Nunnenmacher K, Schultz G, Plant TD (2000) OTRPC4, a nonselective cation channel that confers sensitivity to extracellular osmolarity. Nat Cell Biol 2:695-702.

Suzuki M, Mizuno A, Kodaira K, Imai M (2003) Impaired pressure sensation in mice lacking TRPV4. J Biol Chem 278:22664-22668.

Takahashi K, Sato J, Mizumura K (2003) Responses of C-fiber low threshold mechanoreceptors and nociceptors to cold were facilitated in rats persistently inflamed and hypersensitive to cold. Neurosci Res 47:409-419.

Todaka H, Taniguchi J, Satoh JI, Mizuno A, Suzuki M (2004) Warm temperature-sensitive TRPV4 plays an essential role in thermal hyperalgesia. J Biol Chem

Watanabe H, Vriens J, Suh SH, Benham CD, Droogmans G, Nilius B (2002a) Heat-evoked activation of TRPV4 channels in an HEK293 cell expression system and in native mouse aorta endothelial cells. J Biol Chem 277:47044-47051.

Watanabe H, Davis JB, Smart D, Jerman JC, Smith GD, Hayes P, Vriens J, Cairns W, Wissenbach U, Prenen J, Flockerzi V, Droogmans G, Benham CD, Nilius B (2002b) Activation of TRPV4 channels (hVRL-2/ mTRP12) by phorbol derivatives. J Biol Chem 277:13569-13577.

Watanabe H, Vriens J, Prenen J, Droogmans G, Voets T, Nilius B (2003) Anandamide and arachidonic acid use epoxyeicosatrienoic acids to activate TRPV4 channels. Nature 424:434-438.

Wissenbach U, Bodding M, Freichel M, Flockerzi V (2000) Trp12, a novel Trp related protein from kidney. FEBS Lett 485:127-134.

Xu H, Ramsey IS, Kotecha SA, Moran MM, Chong JA, Lawson D, Ge P, Lilly J, Silos-Santiago I, Xie Y, DiStefano PS, Curtis R, Clapham DE (2002) TRPV3 is a calcium-permeable temperature-sensitive cation channel. Nature 418:181-186. 